\title{
Lean: Introduction of a Quality Improvement Concept into Percutaneous Nephrolithotomy to Improve Efficiency while Maintaining Safety
}

\section{Lean: introducción de un concepto en la nefrolitotomía percutánea para mejorar la eficiencia mientras se mantiene la seguridad}

Nicolas Fernandez ${ }^{10}$ Jessica H. Hannick ${ }^{2}$ Rebeca Escobar ${ }^{3}$ Adolfo Serrano 4

\footnotetext{
${ }^{1}$ Division of Urology, Seattle Children's Hospital, University of Washington, Seattle, WA, United States

2 Division of Pediatric Urology, UH Rainbow Babies and Children's Hospital, Cleveland, OH, United States

${ }^{3}$ Division of Urology, Centro Diagnóstico Urológico, Manizales, Colombia

${ }^{4}$ Department of Urology, Fundación Santa Fe de Bogotá, Bogotá,

Colombia
}

Urol Colomb 2021;30(3):e199-e203.

\begin{abstract}
Address for correspondence Nicolas Fernandez, MD, PhD, Department of Pediatric Urology, Seattle Children's Hospital, 4800 Sand Point Way NE, Seattle, WA, 98105, United States (e-mail: jnfb@uw.edu).
\end{abstract}

\begin{abstract}
Keywords

- quality improvement

- percutaneous nephrolithotomy

- lean methodology
\end{abstract}

Introduction and objective Standardization of surgical interventions reduces complications and costs and positively impacts intra and postoperative outcomes. Implementation of the lean concept, initially proposed in the auto industry, now becomes an interesting approach in the surgical setting. We want to present the results of how percutaneous nephrolithotripsy (PCNL) in a high-level center can be positively impacted by implementing the lean concept.

Methods We evaluated a total of 140 PCNL procedures. Group 1 included all cases operated prior to implementing the lean concept and group 2 was composed of those operated after implementing the lean concept. We looked for all seven sources of waste to identify and modify our practice to improve efficiency and safety. We then collected intraoperative times and compared the ones prior to those after the implementation.

Results After implementing the lean concept, with an average of six PCNL cases per day, a comparison was made to an equivalent number of cases prior to the lean implementation (group 1). The average total operative time for PCNL preintervention was 138 (confidence interval [Cl]: 79 to 170) minutes and postlean intervention was 71.1 (Cl: 43 to 157) minutes. Surgical time (cystoscopy to skin closure) was 36.1 (Cl: 25 to 50 ) minutes prelean and 50 minutes postlean (Cl: 23 to 154). For this last one, received

December 28, 2020

accepted

June 15, 2021

published online

August 13, 2021
DOI https://doi.org/

$10.1055 / \mathrm{s}-0041-1733843$

ISSN 0120-789X.

e ISSN 2027-0119.
(C) 2021. Sociedad Colombiana de Urología. All rights reserved. This is an open access article published by Thieme under the terms of the Creative Commons Attribution-NonDerivative-NonCommercial-License, permitting copying and reproduction so long as the original work is given appropriate credit. Contents may not be used for commercial purposes, or adapted, remixed, transformed or built upon. (https://creativecommons.org/ licenses/by-nc-nd/4.0/)

Thieme Revinter Publicações Ltda., Rua do Matoso 170, Rio de Janeiro, RJ, CEP 20270-135, Brazil 
bilateral procedures were performed. Operative room turnover time was 27.8 ( $\mathrm{Cl}: 21$ to 38) minutes prelean and 5.67 (Cl: 3.5 to 12 ) minutes postlean. Induction time was 16.5 (Cl: 5 to 55$)$ minutes prelean and 5.4 (Cl: 3.5 to 7.5$)$ minutes postlean.

Conclusion Implementation of the lean concept enables optimization of the surgical procedure, allowing hospitals to reduce costs and standardization.

\section{Resumen}

\section{Palabras Clave}

- mejora de la calidad

- nefrolitotomía percutánea

- metodología lean
Introducción y objetivo La estandarización de los procedimientos quirúrgicos reduce complicaciones, costos, y mejora resultados intra y postoperatorios. El concepto lean fue utilizado por primera vez en la industria automotriz. El presente trabajo busca implementar el concepto lean para optimizar el procedimiento de nefrolitotomía percutánea (NLP) en nuestro medio.

Métodos Se realizaron 140 procedimientos de nefrolitotomía percutánea, los cuales se dividieron en 2 grupos: uno en el cual se registraron los tiempos intraoperatorios, y el segundo en que se registraron los tiempos luego de la implementación del concepto lean.

Resultados Durante el período estudiado, se realizaron 70 procedimientos luego de la implementación del concepto lean, y se logró realizar un promedio de 6 procedimientos por día. Se compararon los tiempos operatorios, y se encontró un tiempo operatorio total promedio de 138 (intervalo de confianza [IC]: 79 a 170) minutos prelean, y de 71,1 (IC: 43 a 157) minutos post-lean. El tiempo quirúrgico (cistoscopia a cierre de piel) pre-lean fue de 36,1 (IC: 25 a 50) minutos, y el post-lean fue de 50 (IC: 23 a 154) minutos. Para este último, se trató de procedimientos bilaterales. El cambio de sala fue de 27,8 (IC: 21a 38) minutos pre-lean, y de 5,67 (IC: 3.5 a 12) minutos post-lean. El tiempo de inducción fue de 16.5 (IC: 5 a 55) minutos pre-lean, y de 5.4 (IC: 3.5 a 7.5 ) minutos post-lean.

Conclusiones La implementación del concepto lean permite optimizar el procedimiento, con reducción de costos y estandarización del modelo de atención para cualquier centro asistencial. La movilización de los especialistas en nuestro modelo de atención permite un mayor cubrimiento poblacional de alta calidad.

\section{Introduction}

The lean methodology encompasses an approach to industry that focuses on reducing all forms of wasteful and extra work by eliminating tasks that do not add value to the process. In 1960, Taiichi Ohno first proposed the concept of lean principles, suggesting that the way to become more efficient was to eliminate the 7 sources of waste; waiting/idle time, motion, overproduction, overprocessing, transportation, defects, and inventory. ${ }^{1}$

Over the years, many business sectors have implemented the lean principles, but their application in medicine is more recent. ${ }^{2,3}$ There has been increasing interest in optimizing patient safety while maintaining robust clinical outcomes without affecting efficiency. ${ }^{4}$ This rising interest is mirrored in the trend of government and commercial insurance companies paying based on the quality of service for value, described as value-based care.

While the administrative arms of healthcare drive providers to aim for value-based care, some surgical subspe- cialties, such as urology, have been slow to evaluate their practices. ${ }^{5}$ One of the more technically challenging procedures in endo-urology is the percutaneous nephrolithotomy (PCNL). ${ }^{6,7}$ This procedure requires long learning curves, and many centers do not reach the amount of necessary cases per year to maintain proficiency. ${ }^{8}$ For this reason, it may be of substantial benefit to standardize how PCNL should be performed and to create a system whereby unnecessary tasks are eliminated to increase efficiency and optimize patient safety while maintaining ideal stone-free outcomes.

Herein, we present the evolution of our 16-year multicenter experience performing PCNL procedures, and the implementation of the lean principles to our daily practice. The aim of the project is to evaluate how lean implementation improves operative times of PCNL procedures. ${ }^{9}$

\section{Methods}

A prospective review of 140 PCNL procedures was undertaken. Initially, we divided the patients into two groups (each 
one with 70 cases). Data capturing for both groups followed the same standardized methodology. All surgeries were performed by the same surgeon. Group 1 consisted of PCNL cases performed prior to implementing the lean principles, and group 2 was composed of cases treated after the implementation. The analysis of group 2 was performed during a 3-month period between August and October 2019. Prior to implementing the lean concept to our daily practice, we recorded specific times during the operation for group 1 (total surgical time, anesthetic induction time, total operative time, time used to do cystoscopy and ureteral catheter placement, puncture, and renal access time, and operation room turnover time.) These times were then recorded after the implementation of the lean methodology for group 2. We performed value-stream mapping of our PCNL process and the associated values of each step. We did an arbitrary division starting with a first segment labeled "preoperative/induction," which started when the patient receives preoperative indications one day before surgery until the patient is induced and intubated. The next segment was called "positioning/cystoscopy." This segment started when the endotracheal tube was secured, and the patient was positioned and ended once the ureteral catheter was placed and secured under cystoscopy. Then, the third segment was named "intraoperative." This started when prep- ping and draping was performed and finished with skin closure. The last segment, named "postoperative/turnover," was defined as the segment between the end of skin closure and the entrance of the next patient into the operating room ( - Fig. 1). We then identified wasted time gaps between surgical steps. For each source of waste, we identified steps that could be modified and improved upon.

\section{Results}

During the study period, a total of 70 procedures (group 2) were performed after implementing the lean concept, with an average of 6 PCNL cases per day. A comparison was made to an equivalent number of cases prior to lean implementation (group 1). The average total operative time for PCNL preintervention was 138 (CI 79-170) minutes and postlean intervention was 71.1 (confidence interval [CI] 43157) minutes. Surgical time (cystoscopy to skin closure) was 36.1 (CI 25-50) minutes prelean and 50 minutes postlean (CI 23-154). For the latter, bilateral procedures were performed. Operative room turnover time was 27.8 (Cl 2138) minutes prelean, and 5.67 (CI 3.5-12) minutes postlean. Induction time was 16.5 (CI 5-55) minutes prelean and 5.4 (Cl 3.5-7.5) minutes postlean.

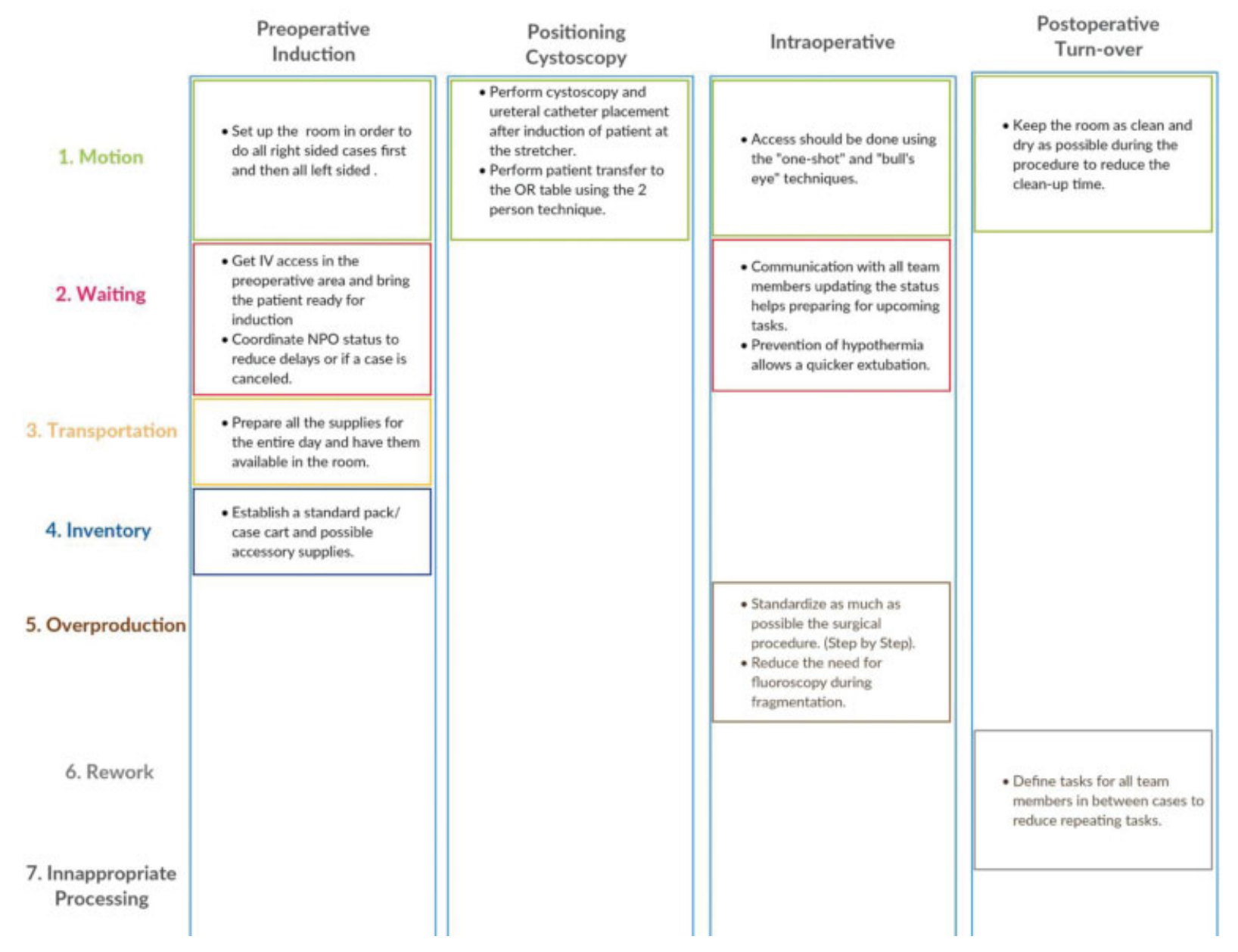

Fig. 1 Stream value mapping for percutaneous nephrolithotripsy procedures. 


\section{Discussion}

For the implementation of the lean concept, we identified the following factors that were changed to improve efficiency and safety in a high-volume PCNL practice.

1. Motion: To reduce unnecessary motion during the process, we identified pre and intraoperative events that were modified. With an average of 6 cases a day, setting up the OR (fluoroscopy, endoscopy tower) in a way that all right-handed cases are operated first followed by the left-handed cases reduces unnecessary operation room display and equipment movement between cases. Furthermore, the entire team must understand the importance of timely waste disposal, as this reduces the need for extra cleaning between cases.

At the beginning of each of our cases, the urology team obtains their own renal access. Some centers, however, may enlist interventional radiology's support for renal access concurrently or in a separate procedure. We have found that performing the puncture ourselves allows for better planning and efficiency given the urologist's intimate knowledge of stone size and location. We prefer using the "bull's eye" technique. ${ }^{10}$ This reduces the need to change the position of the fluoroscopic $\mathrm{C}$-arm, thus reducing extra steps and radiation exposure when obtaining access. We prefer the "one shot" technique for dilatation as it is the fastest method to enter the collecting system. During the fragmentation process, we have found that it is more efficient to fragment the calculi into big pieces for subsequent extraction, instead of dusting them. ${ }^{11}$ Dual lithotriptors are unavailable in most hospitals of the country, so we use ballistic portable lithotripters (LMA StoneBreaker [Cook Medical, Bloomington, IN, USA] and LithoBreaker [Electro Medical Systems, Nyon, Switzerland) because they are more potent, portable devices that have no connections or cables, so time for setup and connections is reduced. Extraction of small pieces is done by washing out fragments. Irrigation is delivered at high speed through the access sheath.

2. Waiting: When it comes to reducing idle waiting times, we identified that preoperative IV access in the preoperative area rather than in the operating room prior to induction contributes substantially to reducing idle time in the OR. Cystoscopy and ureteral catheter placement are done in a stretcher while the patient is intubated. We drape the genital area extensively, and prepping is minimized to the penis or the vaginal introitus. We use a handheld light source to avoid connections

Communication between all team members about the status of the case allows preparation for each member on the next step avoiding unnecessary waits. For example, announcing 15-minute prior to finishing the case, allows the anesthesiologist to prepare for waking the patient up and stopping anesthetics.

Additionally, isolating the patient from the PCNL irrigation fluids may help reduce time to extubation, risk of infection, and cardiovascular events if hypothermia is avoided. ${ }^{12}$

3. Transportation: Waste may be eliminated at this level if all the surgical supplies for the entire day are present in the OR prior to the beginning of the day, and also separated by each individual case. This reduced delays during which the scrubnurse had to leave the room to locate relevant supplies. Considering the lack of specialists available in our country and the highly demanding PCNL technique, we have also found that it is more efficient for the specialist to travel to centers around the country to perform PCNL. More cases can be done if the specialist travels to the centers as opposed to patients traveling to a centralized referral center.

4. Inventory: As mentioned before, a way to reduce a source of waste in the inventory is to have all the supplies available, evaluating what is normally used by the surgeon. We have detected that using the "one-shot" technique at the moment of tract dilation may reduce the need for unnecessary supplies. ${ }^{13}$

5. Overproduction: With regards to this source, it might be important to standardize the intraoperative steps. Some surgeons request to do a forced expiration during ventilation and hold it while doing the puncture. We do not perform this maneuver on a regular basis because once the ventilation is resumed, the access will be causing traction and tension to the parenchyma and may increase the chances of bleeding. It has been our experience that there is no need for a fasciotomy because it may increase the chances of tract bleeding. Once the access is made, the surgeon should try to advance the wire distally into the ureter. If accomplished in the first attempt, we agree it benefits the procedure, but if the anatomy or the stone are not favorable, we suggest not to try until this step is achieved. Instead, we suggest performing what we call the "mold pyelography." (-Fig. 2) For this maneuver, we recommend using a soft wire that coils inside the collecting system creating a "mold" that identifies the shape of the collecting system. Moreover, we do not use a second wire (working/security) as this maneuvering takes time and more X-ray exposition. ${ }^{14}$-Fig. 2.

6. Rework: Using combined contrast (air/contrast) reduces potential extravasation of contrast. When preparing the contrast, we suggest doing it by diluting media to $1: 3$ (contrast/normal saline) and injecting it gently under minimal pressure to avoid pyelovenous backflow into the parenchyma or to create extrarenal extravasation.

Access to the upper pole through an intercostal puncture is always preferred because it allows less tension to the renal parenchyma when navigating inside the kidney. This reduces the need to perform extra punctures in most of the cases.

7. Inappropriate processing: The use of co-axial Alken dilators may be avoided if pneumatic balloon dilators are used. But considering this might be an expensive supply, we have been using the "one-shot" dilation using an Amplatz dilator. ${ }^{15}$ This reduces the extra maneuvers to obtain access.

The structure of our approach from a quality improvement perspective shows how implementation of the lean concept allows improvement in efficiency. We acknowledge that our results come from a high-volume practice and 


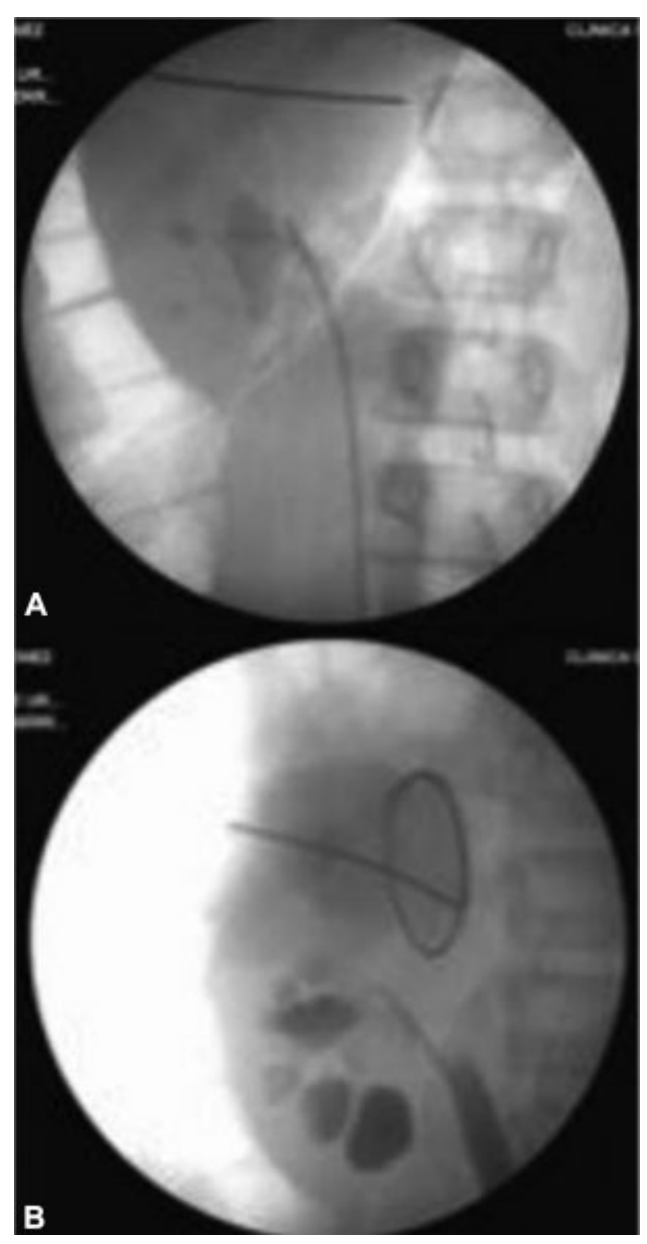

Fig. 2 Mold Pyelogram. (A) Access is achieved, and guidewire is advanced. (B) Guidewire coils inside the collecting system delineating the shape of the collecting system.

implementation of our protocol may be limited. Future directions should include the evaluation of this model and the impact on stone free rates, patient safety, and complication rates.

\section{Conclusion}

Implementation of the lean concept allows to optimize the surgical procedure, allowing for standardization. Once the surgical technique is mastered, surgical times might not be reduced, but other operative times, such as induction times and operative room turnover, are significantly improved by standardization and usage of the lean principles.

\section{Funding}

None.

\section{Conflict of Interests}

The authors declare that they have no conflict of interests.

\section{References}

1 Blackmore CC, Williams BL, Ching JM, Chafetz LA, Kaplan GS. Using Lean to Advance Quality Improvement Research. J Healthc Qual 2016;38(05):275-282 http://www.ncbi.nlm.nih.gov/pubmed/ 26042758 cited 2020Jan17 [Internet]

2 Casey JT, Brinton TS, Gonzalez CM. Utilization of lean management principles in the ambulatory clinic setting. Nat Clin Pract Urol 2009;6(03):146-153

3 What Is Lean Healthcare? [Internet]. New England Journal of Medicine. 2018. Available from: https://catalyst.nejm.org/doi/ full/10.1056/CAT.18.0193

4 Rothstein DH, Raval MV. Operating room efficiency. Semin Pediatr Surg 2018;27(02):79-85

5 Darves-Bornoz AL, Resnick MJ. The evolution of financial incentives in the U.S. health care system. Urol Oncol 2017;35(01):1-4

6 Shabaniyan T, Parsaei H, Aminsharifi A, et al. An artificial intelligence-based clinical decision support system for large kidney stone treatment. Australas Phys Eng Sci Med 2019;42(03): 771-779

7 Desai MR, Kukreja RA, Patel SH, Bapat SD. Percutaneous nephrolithotomy for complex pediatric renal calculus disease. J Endourol 2004;18(01):23-27

8 Tanriverdi O, Boylu U, Kendirci M, Kadihasanoglu M, Horasanli K, Miroglu C. The learning curve in the training of percutaneous nephrolithotomy. Eur Urol 2007;52(01):206-211http://linkinghub. elsevier.com/retrieve/pii/S0302283807000024 cited 2018Dec18 [Internet]

9 Serrano A, Latorre C. Creación de centros de excelencia en nefrolitotomía percutánea. Urol Colomb. 2010;XIX(02):11-22

10 Kyriazis I, Liatsikos E, Sopilidis O, Kallidonis P, Skolarikos AEuropean Section of Urotechnology (ESUT) European Section of Urotechnology educational video on fluoroscopic-guided puncture in percutaneous nephrolithotomy: all techniques step by step. BJU Int 2017;120(05):739-741

11 El-Nahas AR, Almousawi S, Alqattan Y, Alqadri IM, Al-Shaiji TF, AlTerki A. Dusting versus fragmentation for renal stones during flexible ureteroscopy. Arab J Urol 2019;17(02):138-142http:// www.ncbi.nlm.nih.gov/pubmed/31285926 cited 2020Jan17 [Internet]

12 Lenhardt R, Marker E, Goll V, et al. Mild intraoperative hypothermia prolongs postanesthetic recovery. Anesthesiology 1997;87 (06):1318-1323

13 Nour HH, Kamal AM, Zayed AS, Refaat H, Badawy MH, El-Leithy TR. Single-step renal dilatation in percutaneous nephrolithotomy: A prospective randomised study. Arab J Urol 2014;12(03): 219-222http://www.ncbi.nlm.nih.gov/pubmed/26019953 cited 2020Jan17 [Internet]

14 Serrano A, Bravo-Balado A, Díaz AM, Barco-Castillo C, Trujillo CG. How can I get a renal access if I do not have an ultrasound and cannot opacify the collecting system? Another use of the hydrophilic guide wire. Ther Adv Urol 2019;11:1756287219868603

15 Penbegul N, Dede O, Daggulli M, Hatipoglu NK, Bozkurt Y. A novel percutaneous nephrolithotomy (PCNL) set: The 'Economical Oneshot PCNL Set' (Ecoset). Arab J Urol 2017;15(03):199-203. Doi: 10.1016/j.aju.2017.05.003 [Internet] 